LAWRENCE LIVERMORE N A T IO N A L LABORATORY
COAMPS Application to Dispersion Scavenging Problem: Heavy Precipitation Simulation

Hung-Neng S Chin, Richard T Cederwall

May 10, 2004 
This document was prepared as an account of work sponsored by an agency of the United States Government. Neither the United States Government nor the University of California nor any of their employees, makes any warranty, express or implied, or assumes any legal liability or responsibility for the accuracy, completeness, or usefulness of any information, apparatus, product, or process disclosed, or represents that its use would not infringe privately owned rights. Reference herein to any specific commercial product, process, or service by trade name, trademark, manufacturer, or otherwise, does not necessarily constitute or imply its endorsement, recommendation, or favoring by the United States Government or the University of California. The views and opinions of authors expressed herein do not necessarily state or reflect those of the United States Government or the University of California, and shall not be used for advertising or product endorsement purposes.

This work was performed under the auspices of the U.S. Department of Energy by University of California, Lawrence Livermore National Laboratory under Contract W-7405-Eng-48. 


\title{
COAMPS Application to Dispersion Scavenging Problem: Heavy Precipitation Simulation
}

\author{
Hung-Neng S. Chin, and Richard T. Cederwall
}

\author{
Atmospheric Science Division \\ Lawrence Livermore National Laboratory
}

\section{INTRODUCTION}

Precipitation scavenging can effectively remove particulates from the atmosphere. Therefore, this process is of importance in the real-time modeling of atmospheric transport for hazardous materials. To account for the rainfall effect in LLNL operational dispersion model, a modified version of a standard below-cloud aerosol scavenging model has been developed to handle the emergency response in this scenario (Loosmore and Cerdewall, 2003, hereafter referred to as $L C$ ).

Two types of rain data can be used to incorporate precipitation scavenging in the dispersion model; realtime measurements (rain gauge and radar), and model prediction. The former approach has been adopted in LC's study for the below-cloud scavenging problem based on the surface rain measurements. However, the in-cloud scavenging effect remains unresolved as a restriction of available real-time measurements in providing the vertical structure of precipitation systems.

The objective of this study is to explore the possibility to incorporate three-dimensional precipitation structure of forecast data into the dispersion model. Therefore, both in-cloud and below-cloud scavenging effects can be included in LLNL aerosol scavenging model. To this end, a mesoscale model (Naval Research Laboratory 3D weather forecast model, COAMPS) is used to demonstrate this application using a mid-west severe storm case occurring on July 18, 1997.

\section{MODEL AND EXPERIMENT DESIGN}

The Naval Research Laboratory's three-dimensional (3-D) coupled Ocean/Atmosphere mesoscale prediction system (COAMPS) consists of a data assimilation system, a nonhydrostatic atmospheric forecast model, and a hydrostatic ocean model.

In this study, we use only the atmospheric model, which is composed of a compressible form of the dynamics, nest-grid capability, and parameterizations of

\footnotetext{
*Corresponding author address: Dr. Chin, Lawrence Livermore National Lab. (L-103), Livermore, CA 94550; e-mail: chin2@IInl.gov.
}

subgrid-scale turbulence, surface momentum and heat fluxes, explicit ice microphysics, subgrid-scale cumulus clouds, and shortwave and longwave radiation. The terrain-following vertical coordinate is also used to simulate flow over an irregular surface. The reader is referred to Hodur (1997) for further details of COAMPS.

The model domain contains 40 grid points in the vertical, with the grid size varied to maximize resolution at lower levels. The grid spacing of the lowest layer is 4 $\mathrm{m}$, with each successive layer gradually increased to $700 \mathrm{~m}$ at the altitude of $3.086 \mathrm{~km}$. Above this level, a uniform grid size of $700 \mathrm{~m}$ is specified up to the altitude of $11.486 \mathrm{~km}$. Then, the grid size is further smoothly increased to $5.0 \mathrm{~km}$ with the domain top residing at $27.736 \mathrm{~km}$. In the horizontal, a total of four nested domains are adopted in this study. Both zonal and meridional coordinates have 91 grid points for the first and the second nested domains, and 142 grid points for the rests of nested grids. A uniform grid size of $36 \mathrm{~km}$ is used for the outer coarser mesh (nest_1) with a constant size ratio of three to define the inner nest grids. Therefore, the finest grid resolution of the fourth nested domain is $1.333 \mathrm{~km}$ (nest_4).

Constant time steps of 90 and 45 seconds for nonsound and sound wave calculations, respectively, are used in the coarser grids for the time-splitting scheme. The time steps for the finer-grid domains are reduced proportionally to the nest-grid size ratios. The rigid boundary condition is imposed at the vertical boundary. A sponge-damping layer is placed above $14.4 \mathrm{~km}$ to minimize the reflection of internal gravity waves off the rigid upper boundary. The Davies (1976) boundary condition is applied to the lateral boundaries with a nudging zone of seven grid points at each lateral boundary. A time filter with a coefficient of 0.2 is applied to control computational instability associated with the leapfrog time approximation in the model.

\section{INITIAL CONDITIONS}

A well-defined mesoscale rainband occurring at 7UTC July 18, 1997 (2 AM local time) is selected for this case study to assess COAMPS predictability in 
simulating mesoscale convective systems (Fig. 1). The synoptic condition of this event showed that there was no front or other line forcing to be related to this rainband structure. In this study, we conduct a simulation using ETA $40-\mathrm{km}$ data as inputs to drive COAMPS. The simulation starts from 12UTC, July 17 1997, and forecasts for 24 hours. To evaluate the performance of COAMPS, simulation results are compared with the radar measurements from the Central Facility of the DOE ARM program at the Southern Great Plains site.

\section{RESULTS}

Previous research clearly indicates that the dynamic structure of mesoscale convective systems is highly determined by the vertical wind shear and buoyancy of the environment (Weisman and Klemp, 1982 and 1984). The environment with a bulk Richardson number (Ri) less than 35 favors the development of supercellular storms while the multicellular storms tend to develop with Ri between 35 and 240. As the environment has $\mathrm{Ri}$ larger than 240, short-lived convective storms become the preference mode of convection.

Figure 2, 3 and 4 exhibit the evolutions of model environment for convective available potential energy (CAPE), vertical shear of horizontal wind between 0.5 and $5 \mathrm{~km}$ (AGL), and bulk Ri (ratio of CAPE to the square of wind shear), respectively for the nest_4 domain. CAPE is intensified fast as the solar radiation starts to build up the daytime boundary layer. This strong buoyancy forcing acts to effectively lift the surface air parcels to the condensation level for convection to develop in this case (Fig. 2). Once convection develops, it can quickly reduce CAPE and stabilize the local environment. However, the vertical shear of horizontal wind is very week before 18-h of forecast time. Afterward, strong wind shear (larger than $10 \mathrm{~m} / \mathrm{s}$ ) starts to appear in the central portion of model domain (Fig. 3). As a result, the environment provides a favored zone of low bulk Ri for the development of supercellular storm (Fig. 4).

The scatter diagram of the pre-storm environment at the center of nest_4 domain is shown in Fig. 5. A clear, but weak directionally varying shear with height existed below $5 \mathrm{~km}$. Therefore, the resulting mean wind shear vector points to the northeast direction, which is roughly normal to the orientation of convective rain band as seen in Fig. 1. Based on earlier storm studies (Weisman and Klemp, 1982 and 1984), the directionally varying shear acts to develop a splitting storm with stronger convection at the right flank (i.e., to the right of wind shear direction), and leaves weaker convection at the left flank. However, the weak wind shear intensity favors short-lived splitting storm.

The evolution of simulated rainband is depicted in Fig. 6 using the model computed radar reflectivity at the height of $3.8 \mathrm{~km} \mathrm{AGL}$. Following the wind shear direction of the pre-storm environment, new convective cells start to form to the left of the existing convection cluster in the low Ri zone after hour-18 of forecast time. An NW-SE oriented rainband appears two hours later. The structure of this rainband exhibits close resemblance to the observation in both convective and stratiform regions of precipitation (Fig. 1), except for the delay of appearance by 1 hour or so. However, this simulated rainband dissipates shortly as seen in the radar echo (not shown).

Although the orientation of this rainband is normal to the environmental wind shear, the lack of fast band propagation makes this precipitation system not in the category of squall-line systems. However, the formation of band structure under the veering shear environment is very similar to the one seen in typical mid-latitude, sub-tropical and tropical squall-line systems (Weisman and Klemp, 1984; Trier and Parson, 1995; Chin and Wilhelmson, 1998).

To evaluate the possibility of using COAMPS forecast for the in-cloud scavenging parameterization in the dispersion model, the vertical structure of simulated precipitating system is shown in Fig. 7 . The model computed radar reflectivity exhibits two convective cells (> $25 \mathrm{dBZ}$ ) and one wide spreading stratiform region to the right (Fig. 7a). The existence of this stratiform precipitation is due to the melting of falling snow, as debris from earlier convective cells. However, the snow melting of this case did not exhibit a well-known feature of so-called bright melting band (radar reflectivity of 35 $\mathrm{dBZ}$ or so) right below the freezing point level as seen in many mid-latitude and tropical mesoscale convective systems (e.g., Chin, 1994; Chin et al., 1995).

In addition, this stratiform precipitation only appears above $2 \mathrm{~km}$ (AGL). This result is not consistent with radar estimated surface precipitation as seen in Fig. 1. The lack of surface precipitation in COAMPS forecast is due to the drier layer below the mid-level stratiform precipitation layer (Fig. 7b). This drier layer is caused by the induced descending mesoscale flow ahead of the storm. As shown by the arrows in Fig. 7b, part of this descending flow moves into the convective core, and 
the other returns to the surface. This type of scale interaction has been observed in many convective systems. However, the disagreement of stratiform precipitation near the surface between simulation and measurement suggests that the modeled environment may be too drier at mid-levels or the radar derived surface rainfall may not be accurate. Further supplemental data are needed to clarify the possibility.

The sensitivity of horizontal grid resolutions to the model simulation is also assessed in this study. As the resolution increases, the simulated storm structure becomes more realistic. In particular, the coarser resolution of $36 \mathrm{~km}$ is not sufficient enough to resolve the rainband structure. However, the 12-km resolution appears to be the marginal resolution to this band structure as a result of the new development of convective cell to the left of the existing dominant convection (following the wind shear direction).

\section{SUMMARY}

To evaluate the possibility of using COAMPS forecast for in-cloud and below-cloud scavenging effects in LLNL aerosol scavenging model, a modeling study of a mid-latitude precipitating storm is conducted. Results indicate that COAMPS forecast provides very realistic storm structure as seen in many mesoscale convective systems. However, due to the lack of available measurements in providing the vertical structure of this selected storm, it is difficult to make conclusion for clarifying the primary disagreement of surface stratiform precipitation between simulation and radar estimated surface measurements. Nonetheless, the 3-D structure of COAMPS forecast in precipitation field can easily be used to determine the cloud geometry for in-cloud scavenging effect. This aspect is the major barrier to the surface-based measurements. In addition, the realtime feature of COAMPS forecast is another important factor for planning the real accident assessment.

Acknowledgments. This work was supported by the U.S. Department of Energy National Advisory Release
Assessment Program and LLNL LDRD project (02-ERD036), and conducted under the auspices of the U.S. Department of Energy by the University of California, Lawrence Livermore National Laboratory under Contract W-7405-Eng-48.

\section{REFERENCES}

Chin, H.-N. S., 1994: The impact of the ice phase and radiation on a midlatitude squall line. J. Atmos. Sci., 51, 3320-3343.

Chin, H.-N. S., Q. Fu, M. M. Bradley and C. R. Molenkamp, 1995: Modeling of a Tropical Squall Line in Two Dimensions: Sensitivity to Radiation and Comparison with a Midlatitude Case. J. Atmos. Sci., 52, 3172-3193.

Chin, H.-N. S. and R. B. Wilhelmson, 1998: Evolution and structure of tropical squall line elements within a moderate CAPE and strong low-level jet environment. J. Atmos. Sci., 55, 3089-3113.

Hodur, R., 1997: The Naval Research Laboratory's coupled ocean-atmospheric mesoscale prediction system (COAMPS). Mon. Wea. Rev., 125, 14141430.

Loosmore, G., and R. T. Cederwall, 2003: Precipitation Scavenging for Emergency Response Applications: Testing an Updated Model with New Real Time Data. Atmospheric Environment. (Submitted)

Trier, S. B., and D. B. Parsons, 1995: Updraft Dynamics within a numerically simulated subtropical rainband. Mon. Wea. Rev., 123, 39-58.

Weisman, M. L. and J. B. Klemp, 1982: The dependence of numerically simulated convective storms on vertical wind shear and buoyancy. Mon. Wea. Rev., 110, 504-520.

Weisman, M. L. and J. B. Klemp, 1984: The structure and classification of numerically simulated convective storms in directionally varying wind shears. Mon. Wea. Rev., 112, 2479-2498. 
ABRFC radar est $1 \mathrm{mated}$ preclp $\log (\mathrm{mm} / \mathrm{hr} /$

$970718.0700 \quad J \mathrm{D}=199.29$

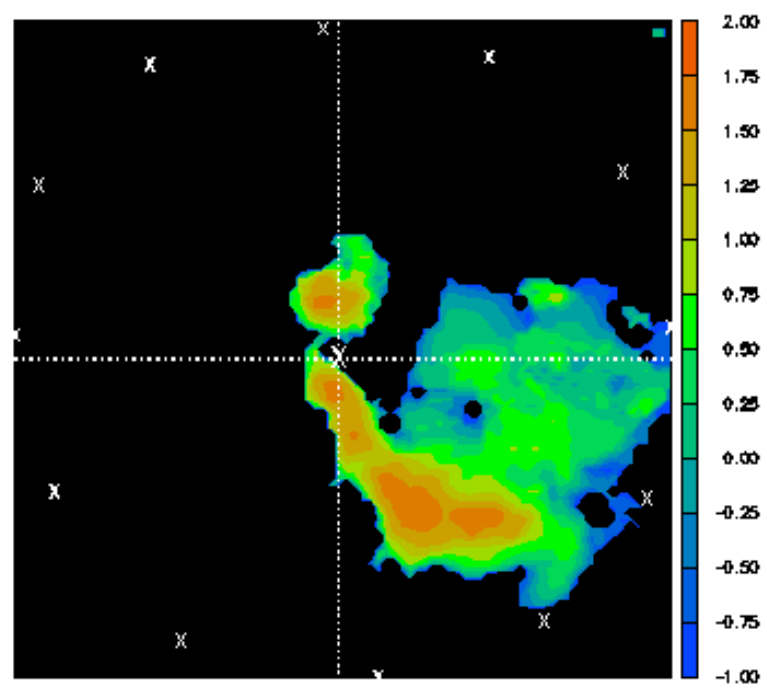

Fig. 1. Radar estimated surface precipitation rate $(\mathrm{mm} / \mathrm{hr})$ in log scale at 07 UTC, July 18 1997. The center cross marks the location of Central Facility at the Southern Great Plains site of the DOE ARM program. The dimension of radar coverage is $180 \mathrm{~km}$ in diameter. 


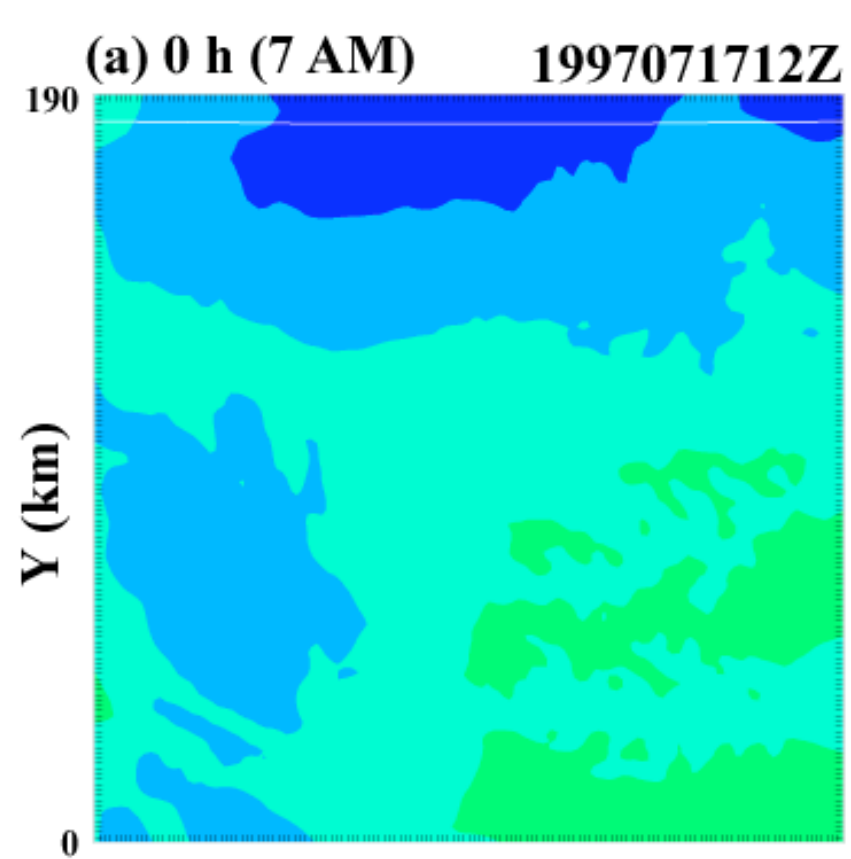

(c) 12 h (7 PM)

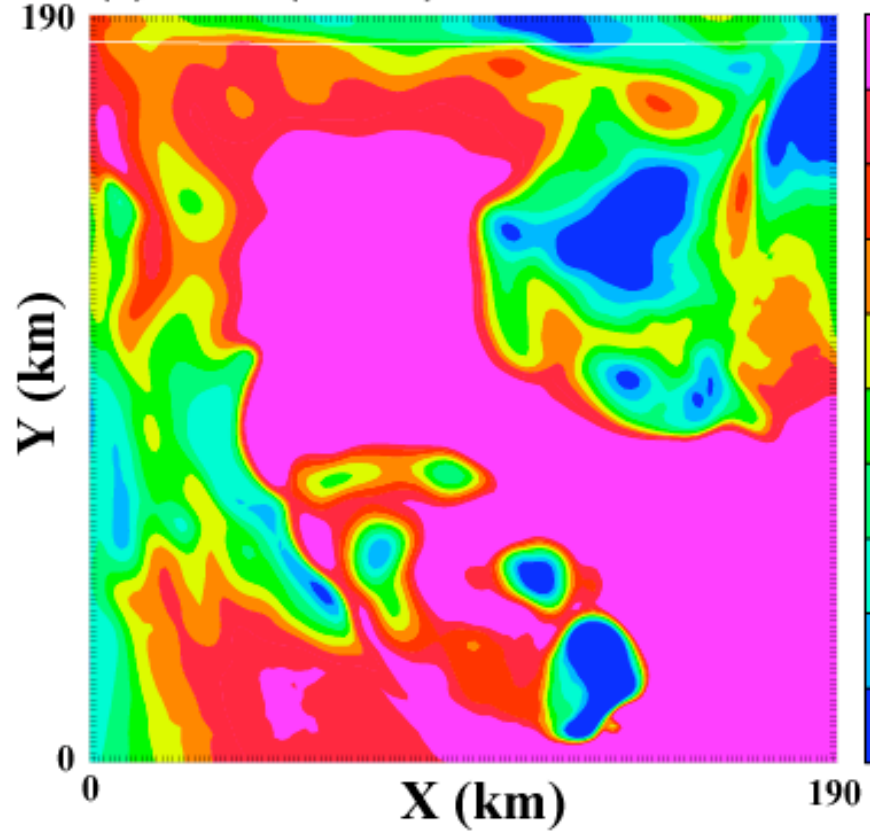

(b) 6 h (1 PM) CAPE $\left(\mathrm{m}^{2} \mathrm{~s}^{-2}\right)$

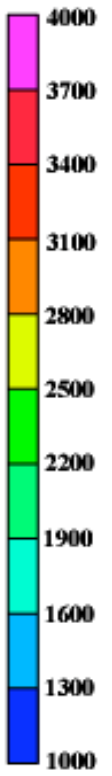

(d) 18 h (1 AM)

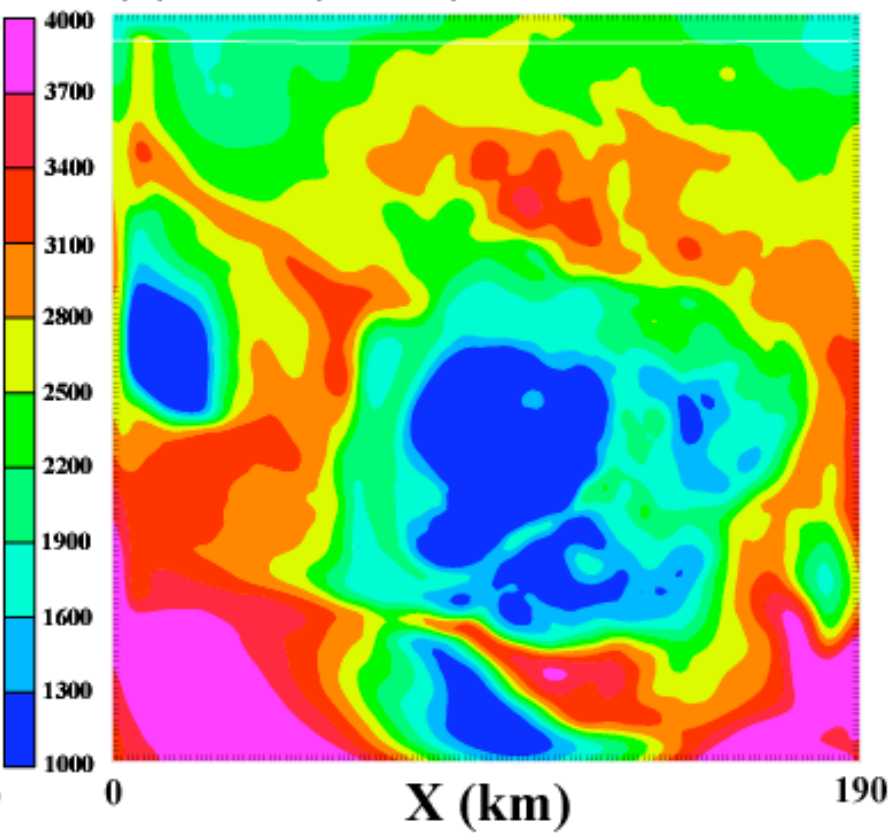

Fig. 2. Time evolutions of convective available potential energy (CAPE) for the nest_ 4 domain $(\square x=1.333$ $\mathrm{km}$ ). (a) Initial time, (b) 6_h forecast, (c) 12_h forecast, and (d) 18_h forecast. 


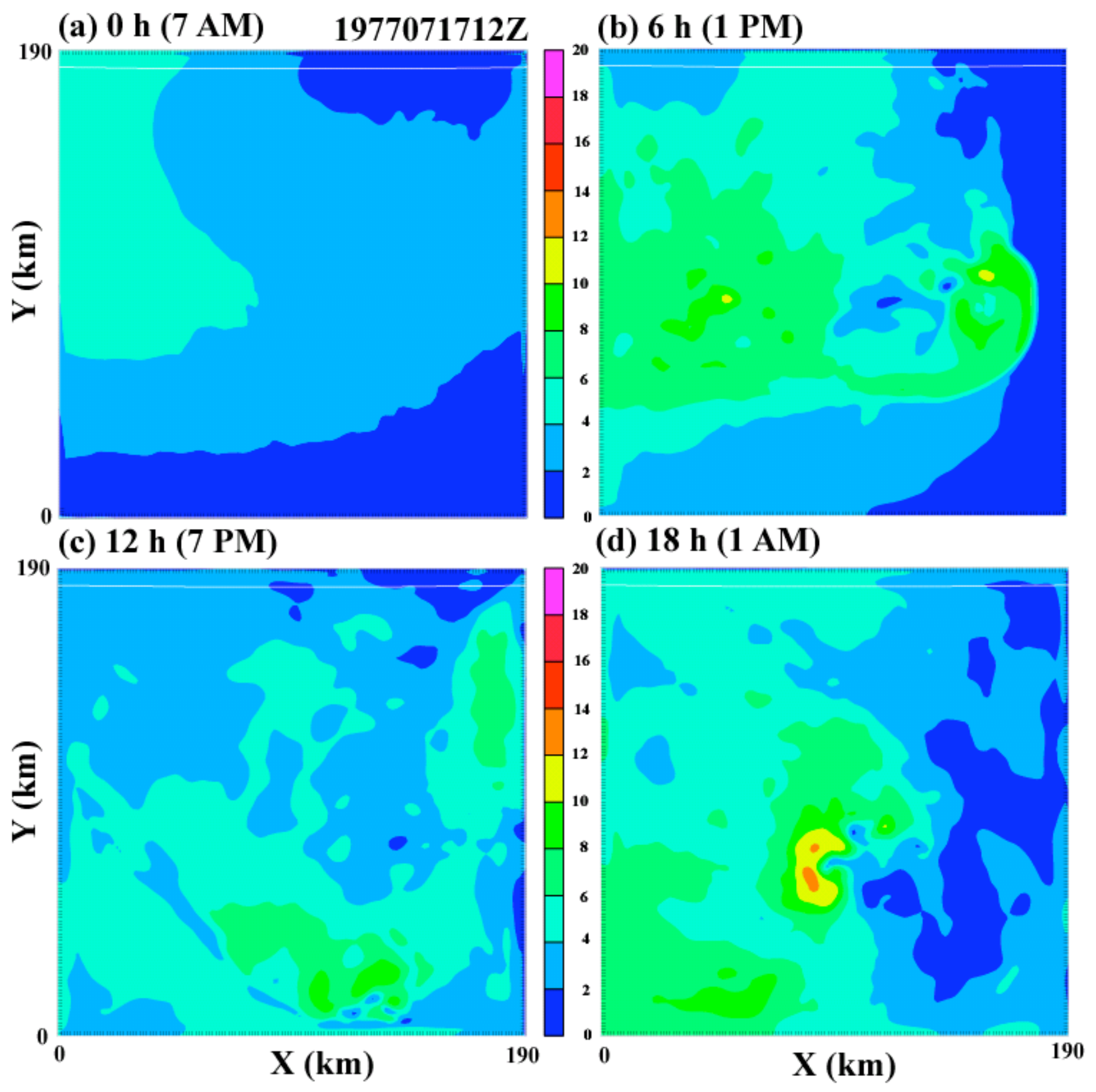

Fig.. 3. Time evolutions of vertical shear of horizontal winds between 0.5 and $5.0 \mathrm{~km}$ (AGL) for the nest_4 domain $(\square x=1.333 \mathrm{~km})$. (a) Initial time, (b) 6_h forecast, (c) 12_h forecast, and (d) 18_h forecast. 

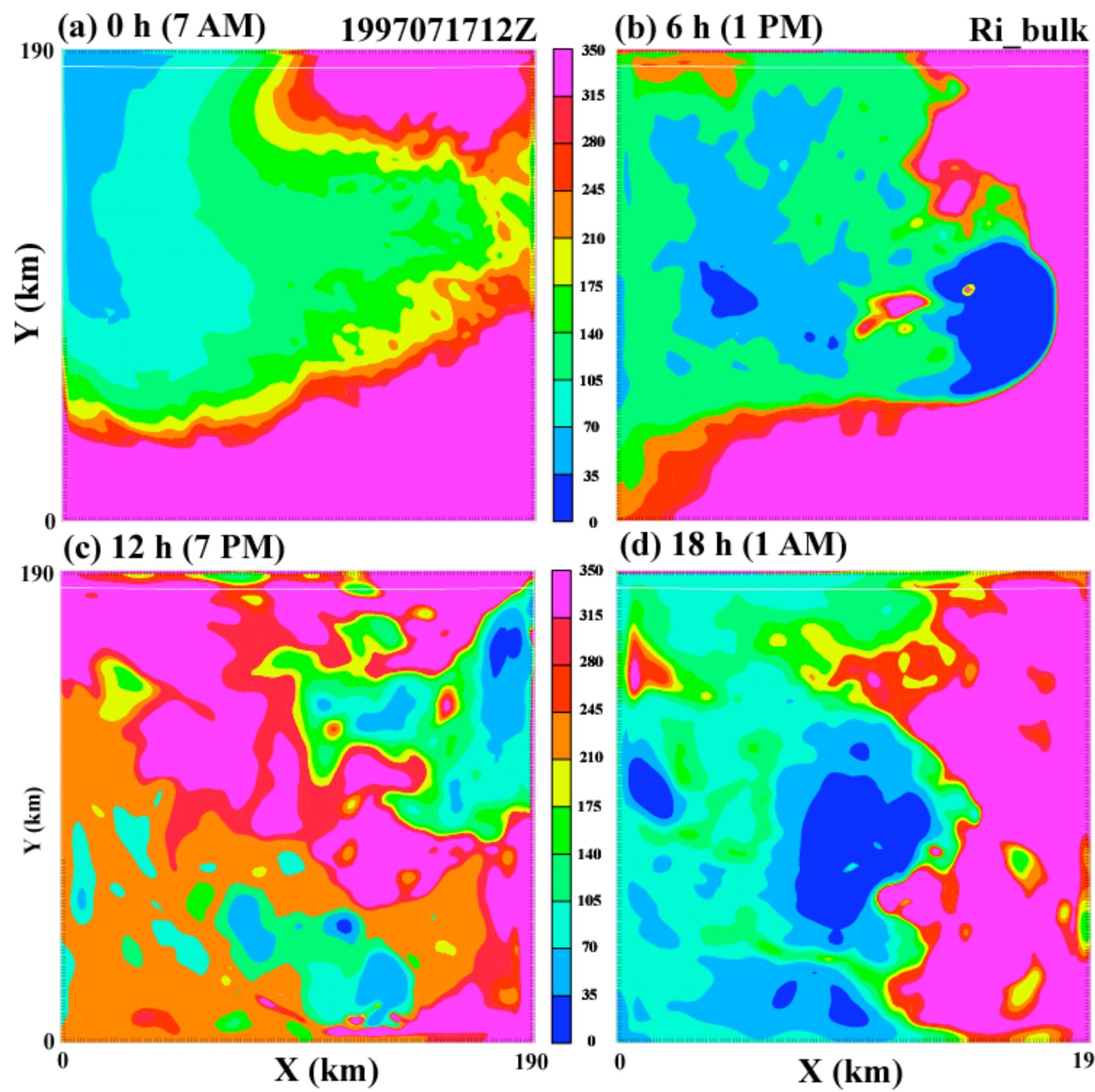

(d) 18 h (1 AM)

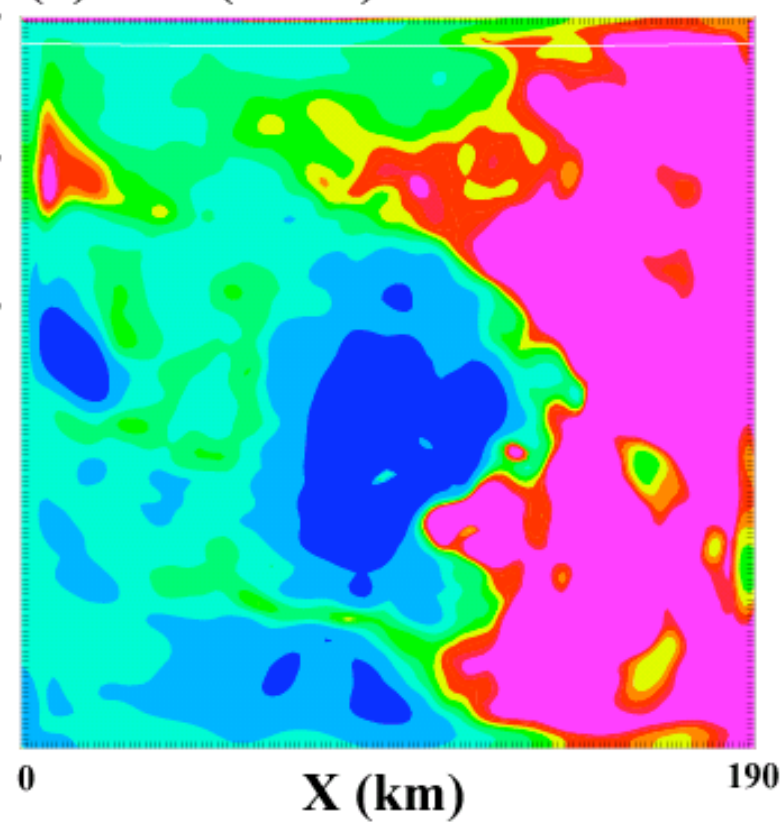

Fig. 4. Time evolutions of bulk Richardson number for the nest_4 domain ( $\square x=1.333 \mathrm{~km})$. (a) Initial time, (b) 6_h forecast, (c) 12_h forecast, and (d) 18_h forecast. 


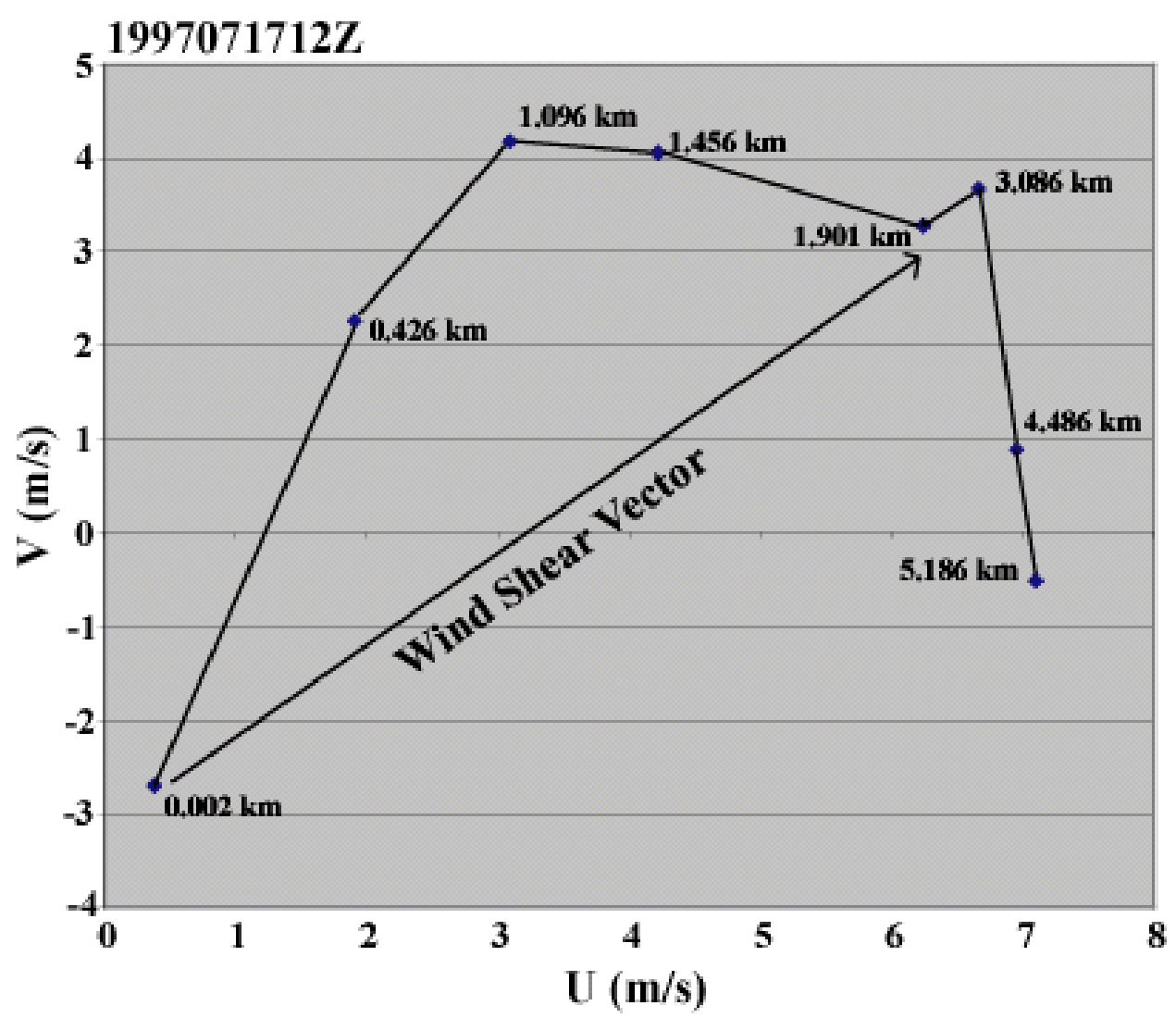

Fig. 5. Scatter diagram of initial condition. Numbers marked beside the points indicate the height of data. The arrow shown is the mean wind shear between 0.5 and $5 \mathrm{~km}$ (AGL). 


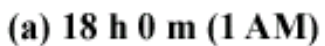

$1997071712 Z$

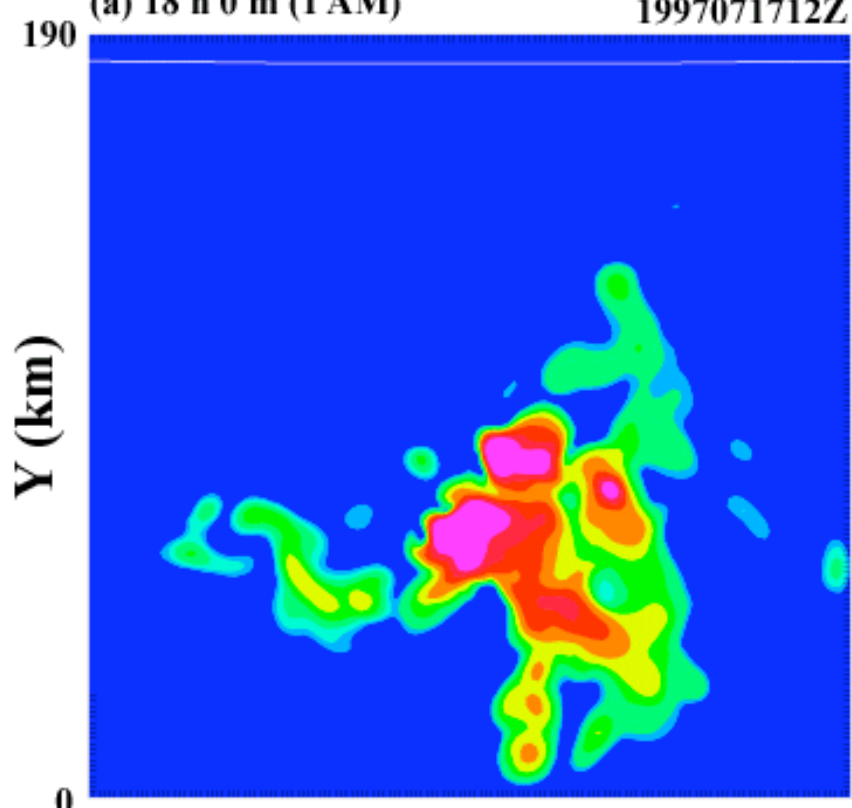

(c) 19 h 30 m (2:30 AM)

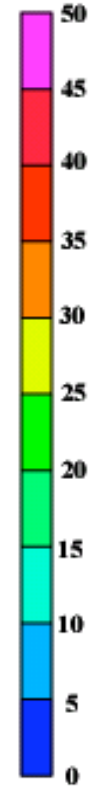

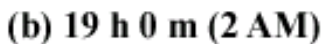

$\mathrm{dBZ}(\mathrm{z}=3.8 \mathrm{~km})$

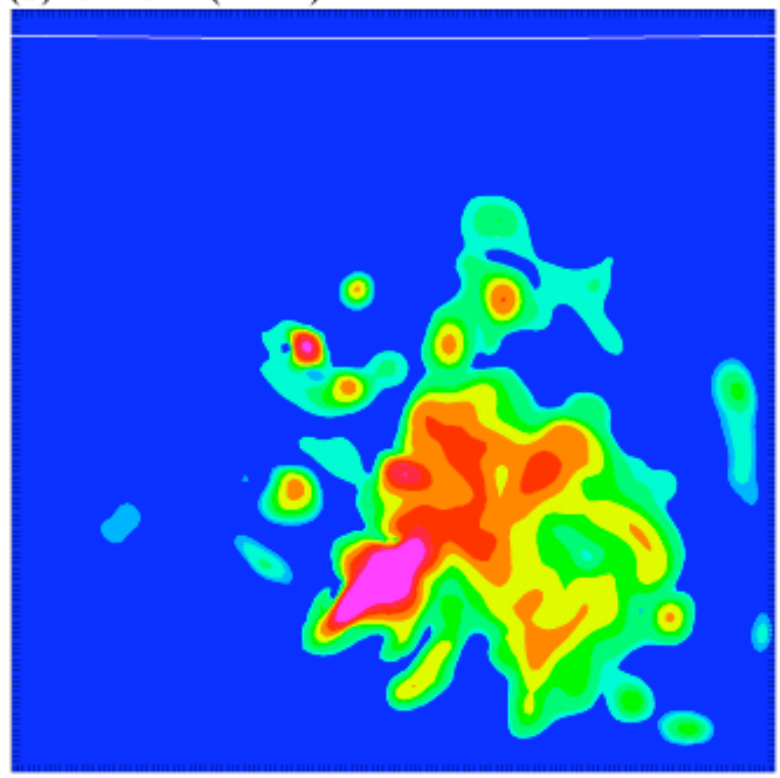

(d) 20 h 0 m (3 AM)
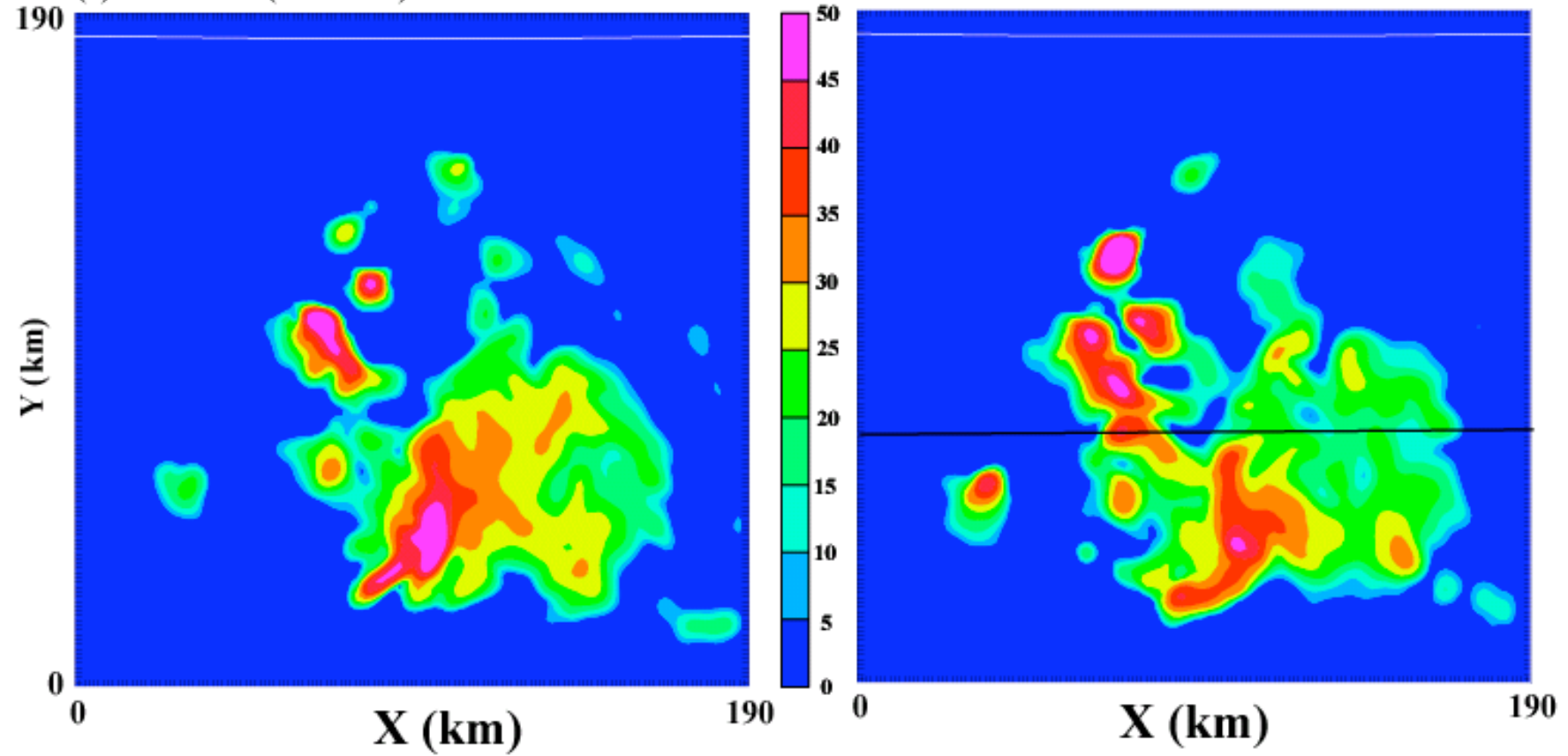

Fig. 6. Time evolutions of model computed radar reflectivity for the nest_4 domain $(\square x=1.333 \mathrm{~km})$. (a) 18_h forecast, (b) 19_h forecast, (c) 19.5_h forecast, and (d) 20_h forecast. 
(a) dBZ

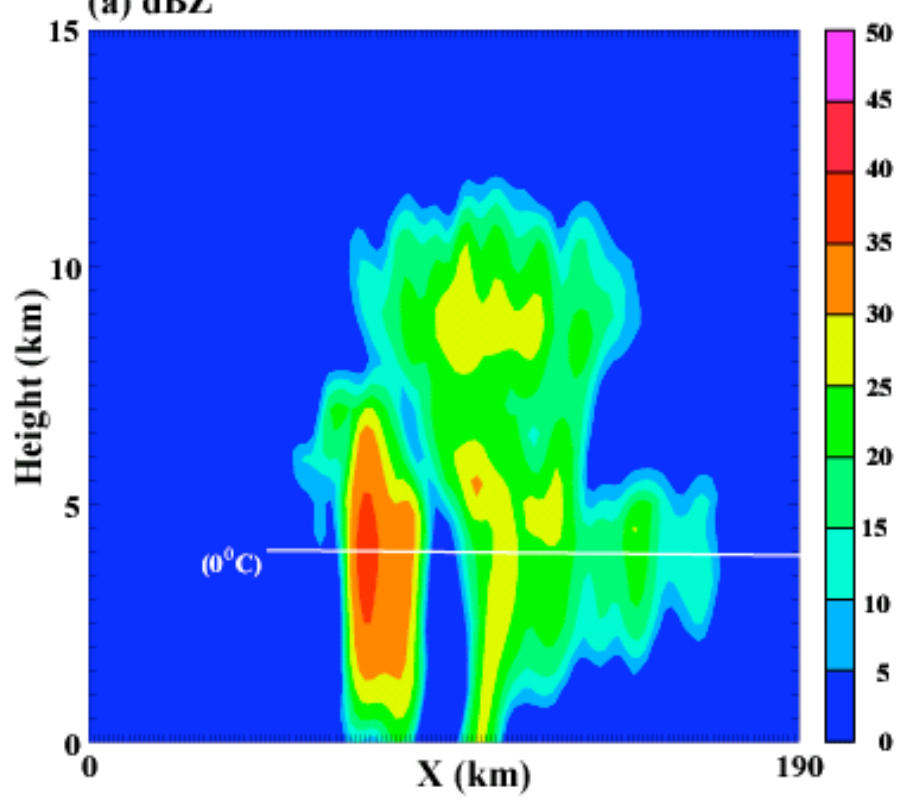

(b) RH (\%)

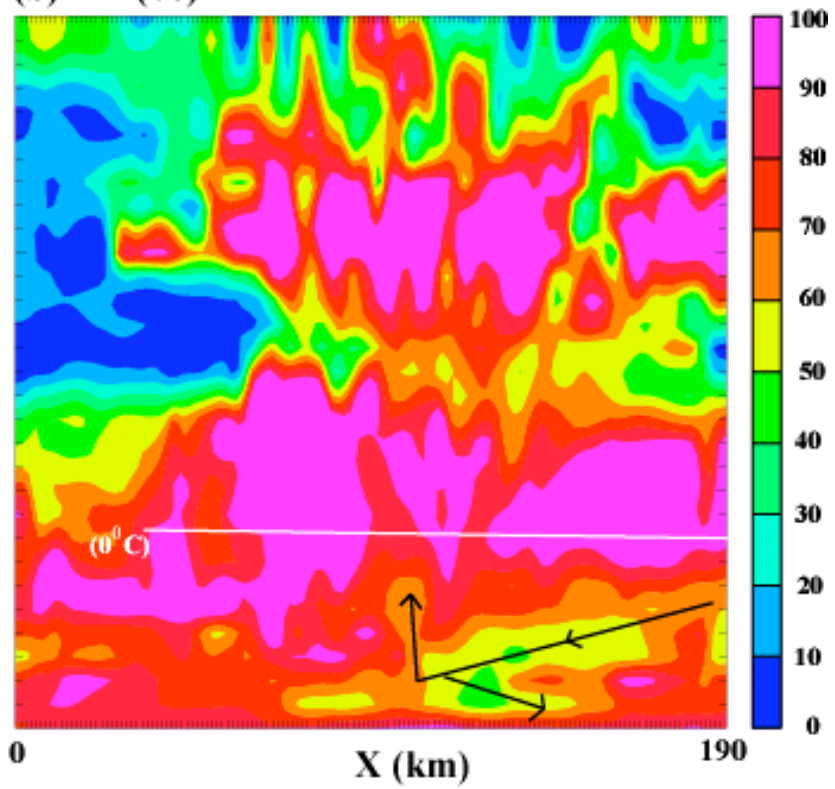

Fig.. 7. Vertical cross-sections of (a) model computed radar reflectivity and (b) relative humidity at 20_h forecast along the black line shown in Fig. 6d. The while lines mark the level of freezing point temperature, and black arrows show the flow movement below the mid-level stratiform precipitation layer. 


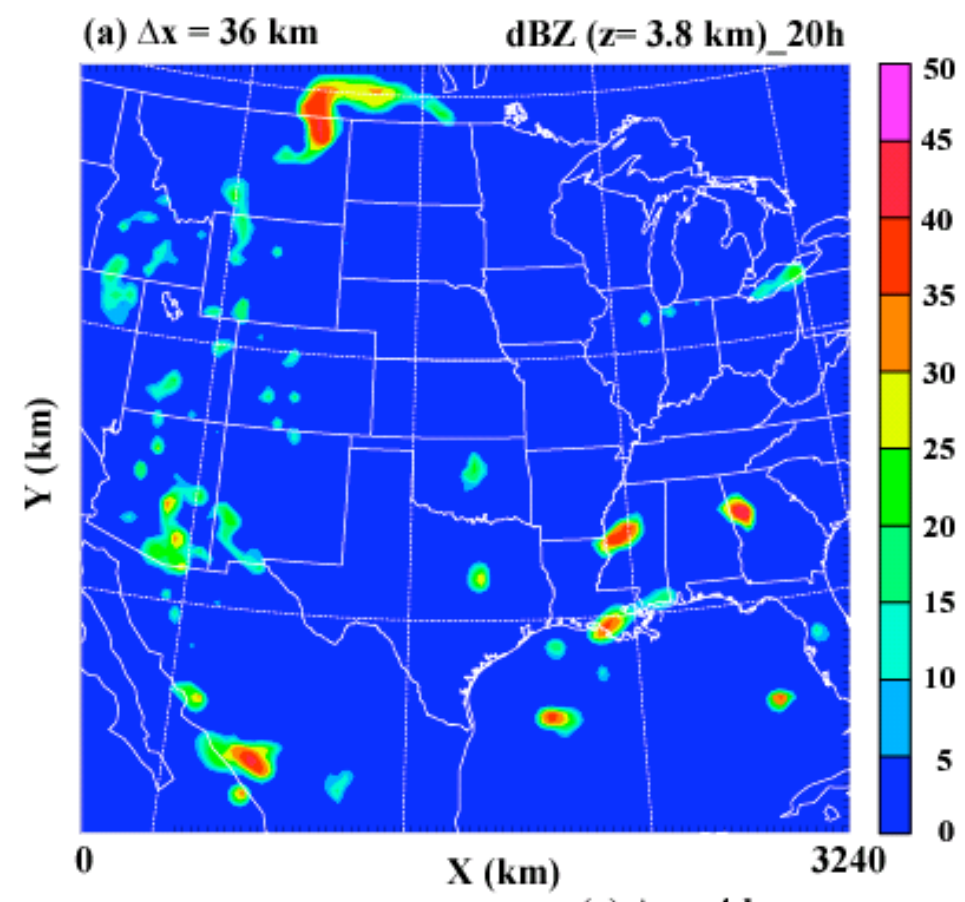

(b) $\Delta x=12 \mathrm{~km}$

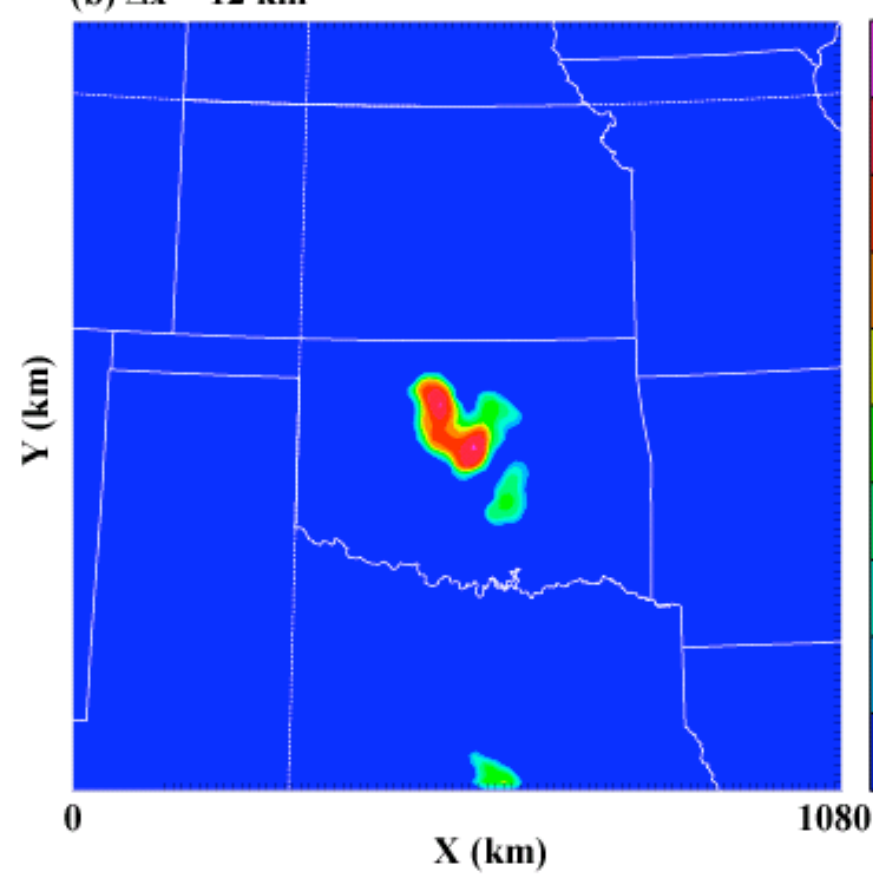

(c) $\Delta x=4 \mathrm{~km}$

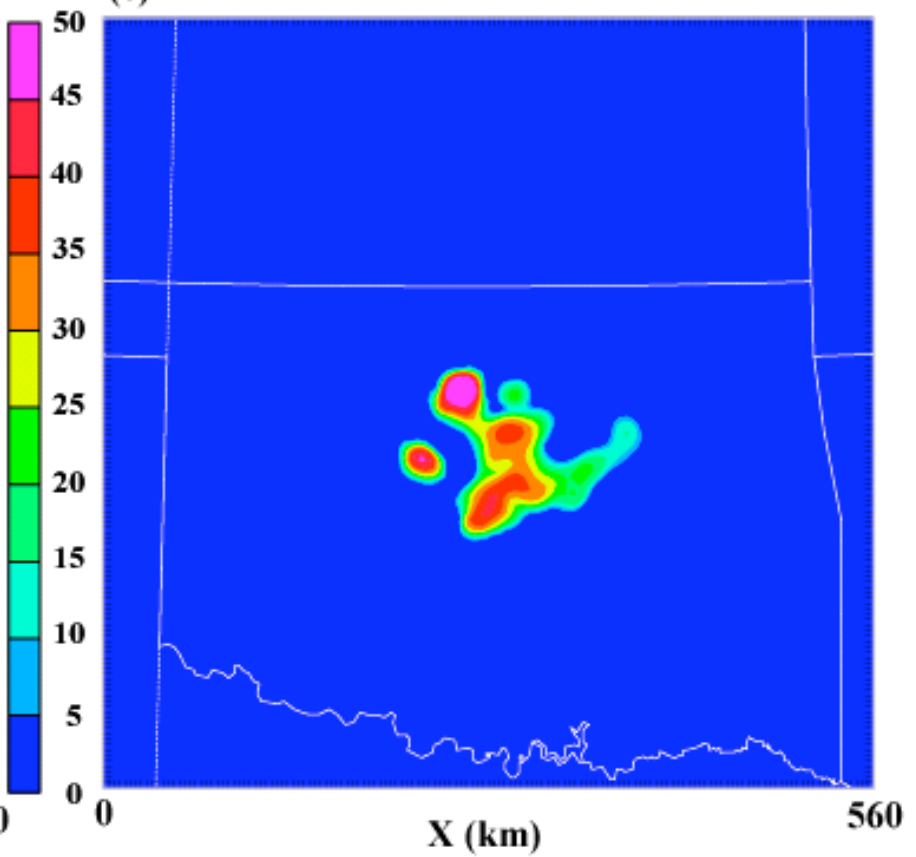

Fig. 8. Horizontal cross-sections of model computed radar reflectivity for different horizontal resolutions at the height of $3.8 \mathrm{~km}$ (AGL) and 20_h of forecast time. (a) $\square \mathrm{x}=36 \mathrm{~km}$, (a) $\square \mathrm{x}=12 \mathrm{~km}$, and (c) $\square \mathrm{x}=$ $4 \mathrm{~km}$. 